\title{
Cardiovascular Health Peaks and Meteorological Conditions: A Quantile Regression Approach
}

\author{
Yohann Moanahere Chiu ${ }^{1,2, *(\mathbb{D}, \text { Fateh Chebana }}{ }^{3}$, Belkacem Abdous ${ }^{4}$, Diane Bélanger ${ }^{3}$ and Pierre Gosselin ${ }^{2,3,4,5}$ \\ 1 Faculty of Pharmacy, Laval University, 1050 Avenue de la Médecine, Quebec, QC G1V 0A6, Canada \\ 2 TEIAC Unity, Quebec National Institute of Public Health, 945 Avenue Wolfe, Quebec, QC G1V 5B3, Canada; \\ pierre.gosselin@inspq.qc.ca \\ 3 Centre Eau Terre Environnement, Institut National de la Recherche Scientifique, 490 Rue de la Couronne, \\ Quebec, QC G1K 9A9, Canada; Fateh.Chebana@ete.inrs.ca (F.C.); diane_belanger@bell.net (D.B.) \\ 4 Department of Social and Preventive Medicine, Faculty of Medicine, Laval University, 1050 Avenue de la \\ Médecine, Quebec, QC G1V 0A6, Canada; belkacem.abdous.1@ulaval.ca \\ 5 Centre de Recherche, Centre Hospitalier Universitaire de Québec, 2875 Boulevard Laurier, \\ Quebec, QC G1V 2M2, Canada \\ * Correspondence: yohann.chiu.1@ulaval.ca
}

Citation: Chiu, Y.M.; Chebana, F.; Abdous, B.; Bélanger, D.; Gosselin, P. Cardiovascular Health Peaks and Meteorological Conditions: A Quantile Regression Approach. Int. J. Environ. Res. Public Health 2021, 18, 13277. https://doi.org/10.3390/ ijerph182413277

Academic Editor: Isidro A. Pérez

Received: 29 September 2021 Accepted: 10 December 2021 Published: 16 December 2021

Publisher's Note: MDPI stays neutral with regard to jurisdictional claims in published maps and institutional affiliations.

Copyright: (c) 2021 by the authors. Licensee MDPI, Basel, Switzerland. This article is an open access article distributed under the terms and conditions of the Creative Commons Attribution (CC BY) license (https:// creativecommons.org/licenses/by/ $4.0 /)$.
Abstract: Cardiovascular morbidity and mortality are influenced by meteorological conditions, such as temperature or snowfall. Relationships between cardiovascular health and meteorological conditions are usually studied based on specific meteorological events or means. However, those studies bring little to no insight into health peaks and unusual events far from the mean, such as a day with an unusually high number of hospitalizations. Health peaks represent a heavy burden for the public health system; they are, however, usually studied specifically when they occur (e.g., the European 2003 heatwave). Specific analyses are needed, using appropriate statistical tools. Quantile regression can provide such analysis by focusing not only on the conditional median, but on different conditional quantiles of the dependent variable. In particular, high quantiles of a health issue can be treated as health peaks. In this study, quantile regression is used to model the relationships between conditional quantiles of cardiovascular variables and meteorological variables in Montreal (Canada), focusing on health peaks. Results show that meteorological impacts are not constant throughout the conditional quantiles. They are stronger in health peaks compared to quantiles around the median. Results also show that temperature is the main significant variable. This study highlights the fact that classical statistical methods are not appropriate when health peaks are of interest. Quantile regression allows for more precise estimations for health peaks, which could lead to refined public health warnings.

Keywords: quantile regression; cardiovascular diseases; health peaks; meteorological conditions; environmental health; heatwaves

\section{Introduction}

Cardiovascular diseases (CVDs) are the second cause of all deaths behind cancers [1] in Canada. In Québec, they are the second cause for all hospitalizations, whereas cancers are the fifth [2]. The number of hospitalizations due to CVDs has been constantly increasing each year by $2.3 \%$ on average since 2005 [3]. Therefore, they represent a major public health challenge. This situation is not uncommon in developed countries, since CVDs are the first cause of death in the world [4]. Therefore, CVDs comprehension, analysis, and prevention remain significant tasks [5,6].

Various factors can influence CVDs. Life habits such as smoking, nutrition or sport practice are known to play important roles [7-9]. On the other hand, atmospheric pollution (e.g., ozone or particulate matter) is strongly associated with CVD occurrence [10]. It is now widely accepted that air pollution has a predominant impact on CVDs, both indoor and outdoor [11,12]. In addition, a large body of literature dealing with impacts of meteorological 
conditions on CVD occurrence such as cold exposure, heatwaves, and diurnal temperature variations is available [13]. Snowfall and humidity are also linked to a higher CVD occurrence $[14,15]$. Moreover, those impacts are also present in Québec, especially regarding temperature [16-18]. However, climate change, by modifying the meteorological variables distribution, may also change those established relationships. In Québec, a significant increase in mean temperatures is, among others, expected by 2050 [19] with the number of hot days $\left(\geq 30^{\circ} \mathrm{C}\right)$ likely to be multiplied by a factor of three. Consequently, heatwaves, which are linked to CVD occurrences, will increase in intensity and frequency. Thus, it is crucial to properly quantify relationships between peaks and meteorological conditions in order to promote population and health services adaptation.

Most of the available studies use statistical models that implicitly focus on mean health events, not specifically peaks. This is a necessary process in order to understand relationships between a health issue and meteorological variables, notably for CVD surveillance. Nevertheless, health peaks (or simply peaks) are not correctly analyzed by those models. Those specific observations lie far from average events and their modeling using statistical models based on the mean can be misleading (results from mean-based regressions cannot be extended to noncentral locations; [20]). Furthermore, they are by definition scarce and they can have heavy consequences on the health system (e.g., emergency departments overflow [21]), which should warrant studies on their own. Few studies examine the extreme nature of health variables from a statistical modeling point of view and they usually focus on peak series once they have been extracted from the datasets [22-24]. Although peaks have strong implications, they are usually not studied from an overall point of view. They can also be analyzed from a descriptive (without modeling) and local point of view for a given extreme event, such as the 2003 European heatwave [25]. Quantile regression $(\mathrm{QR})$ is a statistical model which employs all the observations and would allow comparing the impacts of meteorological variables on average events as well as on health peaks with higher quantile order [26].

The QR model can explore not only the conditional median (as a measure of central tendency), but all quantiles of the dependent variable. Since peaks can be defined as high quantiles, $\mathrm{QR}$ is appropriate to investigate in-depth the conditional distribution of peaks. Moreover, an independent variable could have a significant effect in one quantile, whereas it would not be so in another quantile. Studying only the conditional mean actually "dilutes" information related to the rest of the conditional distribution, especially concerning peaks. QR has been used in public health, but not to explore relationships with meteorological conditions (even less so concerning CVDs). QR is popular when it comes to studying indicators that may have heterogeneous effects. In health sciences, QR has shown the ability to discover heterogeneous effects of independent variables such as air pollution or socioeconomic factors on various health issues [27-29]. This nonhomogeneous influence over different quantiles cannot be highlighted by standard linear regression, which estimates only the conditional mean (as does any other mean-based regression such as the Poisson regression [26]). On the other hand, by using QR, the whole conditional distribution of a health outcome can be reproduced, and comparisons of multiple quantiles can then take place. The objective of this study is thus to examine the impact of meteorological conditions on CVD morbidity and mortality with QR, focusing on health peaks (high quantiles) and their differences with other quantiles, relative to the whole conditional distribution.

The rest of this paper is organized as follows. Available data and methods are described in Section 2, while the results are shown in Section 3. Discussion and limitations are presented in Section 4. Finally, Section 5 presents the conclusions of this study.

\section{Materials and Methods}

This section describes the data and statistical methods used in this study. A more exhaustive description is given in the complete research report of Chiu et al. [30]. 


\subsection{Data}

The study area is Montreal metropolitan community in Canada (abbreviated as Montreal, Figure 1), with 3,994,990 inhabitants in 2018. In this study, health and meteorological sets are used. The daily number of hospitalizations and deaths due to CVDs are the dependent variables, while daily meteorological variables are the independent variables.

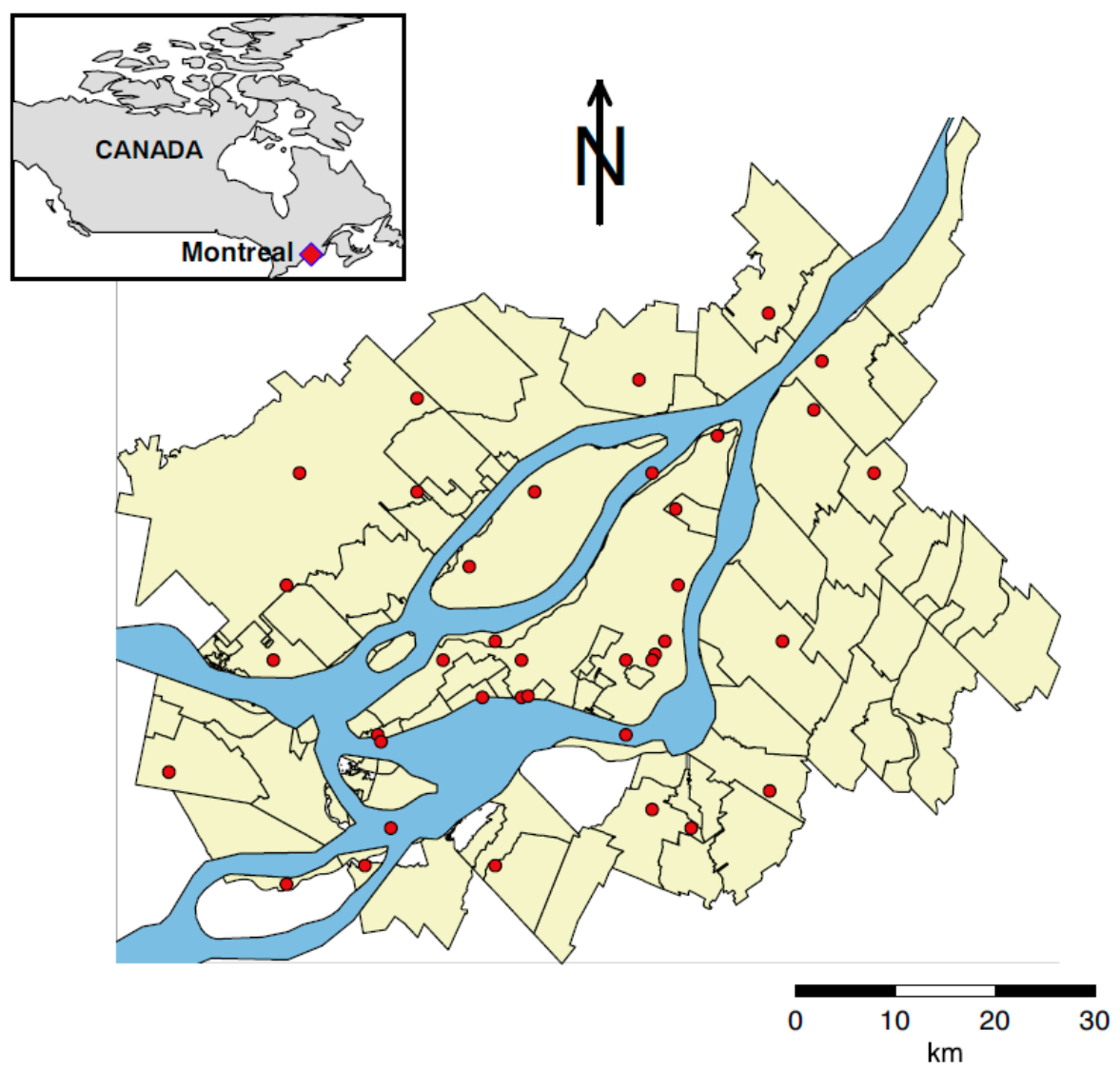

Figure 1. Montreal metropolitan community (Canada). Red dots are the meteorological stations used for measuring meteorological variables.

\subsubsection{Health Data}

Health data are the daily total of CVD hospitalizations and deaths. Daily raw data were provided by the National Institute of Public Health of Québec (Institut national de santé publique du Québec, INSPQ, Québec (QC), Canada). Versions 9 and 10 of the International Classification of Diseases (ICD) were used to classify hospitalization (main and secondary diagnoses), and death (main diagnosis) causes in order to select only the deadliest CVDs for our study (Table 1). The transition from ICD-9 to ICD-10 occurred in April 2006 for the hospitalization files and in January 2000 for the death files. Hospitalizations and deaths were summed to obtain daily numbers of events. Thus, one health datum is either a daily total number of hospitalizations or deaths. Hospitalizations range from 1996 to 2006 (4077 days) inclusively, while deaths range from 1981 to 2011 (11,322 days), resulting in 4077 daily total hospitalizations and 11,322 daily total deaths. Corresponding descriptive statistics are summarized in Table 2. 
Table 1. ICD-9 and ICD-10 for considered CVDs in this study.

\begin{tabular}{ccc}
\hline Most Deadly CVDs & ICD-9 & ICD-10 \\
\hline Ischemic heart diseases & $410-414$ & I20-I25 \\
\hline Heart failure & 428 & I50 \\
\hline & 362.3 & G45.x (excluding G45.4) \\
Cerebrovascular diseases & 430 & H34.0 \\
Transient cerebral ischemia & 431 & H34.1 \\
& $434 . x$ & I60.x \\
& $435 . x$ & I61.x \\
& 436 & I63.x (excluding I63.6) \\
\hline
\end{tabular}

Table 2. Descriptive statistics for daily CVD deaths and hospitalizations in Montreal.

\begin{tabular}{ccc}
\hline & Deaths & Hospitalizations \\
\hline Minimum & 3 & 49 \\
\hline Maximum & 53 & 220 \\
\hline Mean & 17 & 131 \\
\hline Median & 17 & 136 \\
\hline $75 \%$ quantile & 20 & 158 \\
\hline $90 \%$ quantile & 24 & 172 \\
\hline
\end{tabular}

\subsubsection{Meteorological Data}

Meteorological data from 1981 to 2011 are provided by Environment Canada and have been matched to deaths and hospitalizations. Daily series of temperature, atmospheric pressure (pressure), relative humidity (humidity), total precipitations, and snow height are available (Table 3). Of note, snow height is measured during the winter, while total precipitations are measured all year round. They were measured over multiple meteorological stations in Montreal and spatially averaged. Giroux et al. [31] found no advantage in using weighted kriging instead of the spatial mean in this area. Corresponding descriptive statistics are given in Table 4 . Montreal is in a humid continental climate (http:/ / mddelcc.gouv.qc.ca/climat/normales/climat-qc.htm, accessed on 9 December 2021) where summers are hot and humid while winters can be severely cold.

Maximal values for temperature, humidity and pressure have been used to study the impact of meteorological variables, but mean and minimal values have also been investigated with only minor changes in the results [30]. In this study, maximal values have been chosen to illustrate best how QR can be relevant to public health studies.

Table 3. Meteorological variables description.

\begin{tabular}{|c|c|c|}
\hline Variable & Type & Unit \\
\hline Maximal temperature & \multirow{3}{*}{ Daily data } & Celsius degrees \\
\hline Total precipitations & & Millimeter \\
\hline Snow height & & Centimeters \\
\hline Maximal atmospheric pressure & \multirow{2}{*}{ Hourly data } & Kilopascals \\
\hline Maximal relative humidity & & Percentages $(\%)$ \\
\hline
\end{tabular}


Table 4. Descriptive statistics for meteorological variables in Montreal from 1981 to 2011.

\begin{tabular}{cccccc}
\hline & Temperature & Humidity & Pressure & Precipitations & Snow \\
\hline Minimum & -26.5 & 34.0 & 99.1 & 0.0 & 0.0 \\
\hline Maximum & 35.0 & 100.0 & 105.2 & 89.8 & 79.2 \\
\hline Mean & 11.4 & 81.6 & 102.0 & 2.8 & 6.8 \\
\hline Median & 12.2 & 84.0 & 101.9 & 0.3 & 0.0 \\
\hline $75 \%$ quantile & 22.4 & 91.8 & 102.5 & 3.0 & 8.9 \\
\hline $90 \%$ quantile & 26.8 & 96.0 & 103.0 & 8.9 & 27.4 \\
\hline
\end{tabular}

\subsection{Methods}

In the rest of this paper, $q$ refers to a quantile order $(0<q<1)$. For a complete description of QR, the reader is referred to the book of Koenker [26]. Let $Y$ be the dependent variable and $X_{1}, \ldots X_{p}$ be the independent variables (in this study, the health variables and the meteorological variables, respectively), then the QR model is defined as:

$$
Q_{y}\left[q \mid x_{1}, x_{2}, \ldots, x_{p}\right]=\beta_{0}(q)+\beta_{1}(q) x_{1}+\beta_{2}(q) x_{2}+\ldots+\beta_{p}(q) x_{p}
$$

for any quantile $0<q<1$. In contrast to a classical regression, coefficients $\beta_{0}(q), \beta_{1}(q), \ldots$, $\beta_{p}(q)$ vary with $q$. Their interpretation is similar to that in the classical regression, though only valid in one given quantile. They are obtained by minimizing a sum of weighted absolute residuals [32], whereas classical mean regression is usually solved by ordinary least squares or by maximum likelihood. Unlike the latter, QR does not assume normality or homoscedasticity, which makes QR a more robust regression [33]. Confidence intervals (CI) for estimated coefficients are computed using the inverse rank method [26].

Considered quantile orders in this study spread out from $q=0.01$ to $q=0.99$ with a 0.025 step. We used this step in order to explore the health variable conditional distribution in-depth, thus leading to a level of detail that would not be attained by mean-based regression. This study defines a death or hospitalization peak as an observation corresponding to a conditional quantile greater than $90 \%$, as an analogy to the meteorological definition of extreme [34]. Therefore, in the case of our data, death and hospitalizations peaks are defined as days with a total of at least 24 deaths and 172 hospitalizations, respectively (Table 2). The independent variable effects are then compared with the effects in lower conditional quantiles.

Lags are considered for meteorological variables, as their impacts on health can be delayed $[16,35,36]$. We explored the following lags: 0 (same day exposure), 3,7 , and 14 days. All models controlled for seasonality [37,38], though we did not conduct separate analyses (e.g., summer and winter $[39,40]$ ) in order to produce the entire conditional distribution and to not decrease statistical power in the high quantiles. All results are obtained using the statistical software R (R Foundation for Statistical Computing, Vienna, Austria) and quantreg package (v5.85). Meteorological variables are standardized (i.e., centered and divided by their standard deviation) in order to facilitate interpretations as the meteorological variables have different measure scales (Table 3). The statistical significance level is set at $\alpha=5 \%$.

\section{Results}

QR estimation results are presented in this section for hospitalizations and deaths in Montreal. Results are described for each meteorological variable.

\subsection{Hospitalizations}

Results are shown in Figure 2. QR coefficients in the y-axis are plotted versus quantiles in the x-axis; each column represents a given lag $(0,3,7$, and 14 days) for each meteorological variable. Regarding temperature, the coefficient curve exhibits a similar pattern 
over the different lags; it starts at a negative value close to 0 , decreases until the $10 \%$ quantile, increases until the $40 \%$ quantile and decreases again up to the highest quantiles (the peaks). Coefficients are non-significant around the $1 \%$ and $40 \%$ quantiles, whereas in other quantiles an increase in temperature is associated with a decrease in hospitalizations. $\mathrm{CI}$ for the classical regression and QR estimations are crossing overall, with the exception of peaks higher than the $95 \%$ quantile at lag 7 and 14 . In those peaks, differences are significant, and the classical regression estimation underestimates temperature influence. Besides, QR coefficients are the strongest in peaks, more than twice the values for quantiles in the median vicinity.

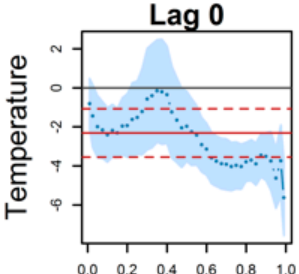

Quantile

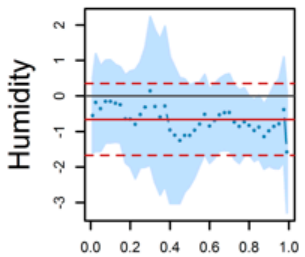

Quantile

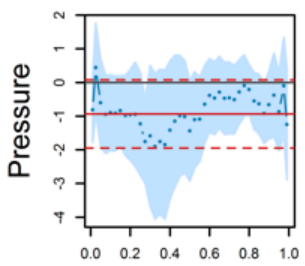

Quantile

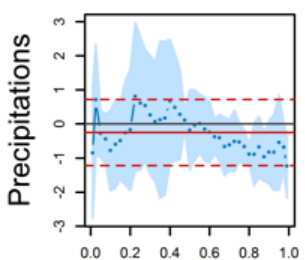

Quantile

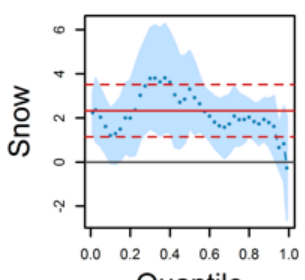

Quantile
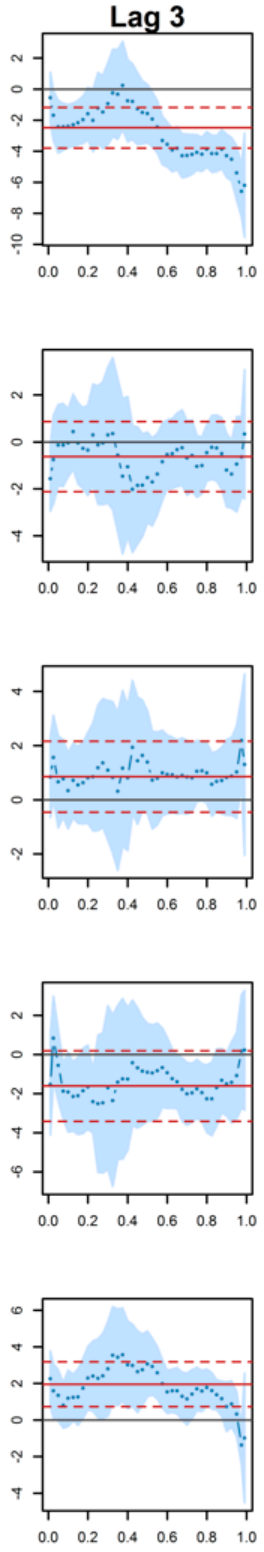

$\begin{array}{llllll}0.0 & 0.2 & 0.4 & 0.6 & 0.8 & 1\end{array}$
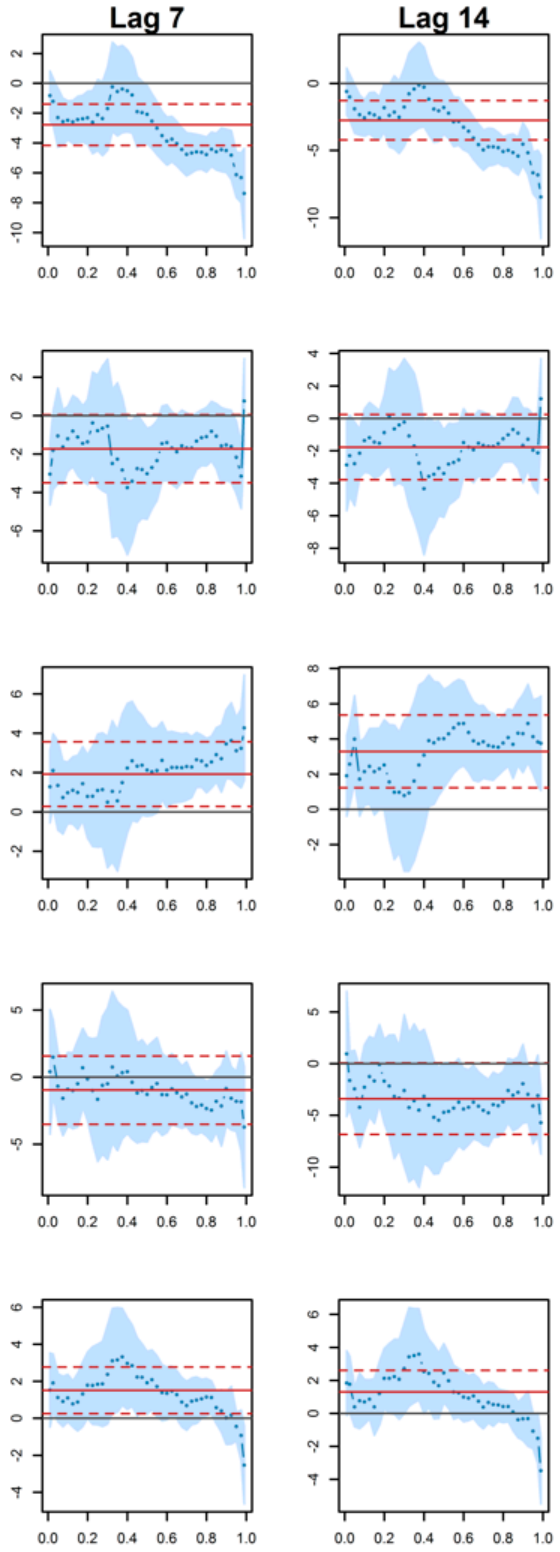

Figure 2. QR (blue dots) and classical mean regression (red full line) coefficients against quantiles, for hospitalizations in Montreal. 95\% confidence intervals are shown in light blue for QR and in red dashed lines for classical mean regression.

An inverse association between hospitalizations and humidity is observed at every lag (negative estimated coefficients), except in peaks at lags 3, 7, and 14. However, coefficients are mostly non-significant. There are some exceptions, such as lags 7 and 14, around the median. For peaks (higher than the $95 \%$ quantile) at lag 7 , the humidity effect is 
significant with negative estimated coefficients. In this case, a classical regression finds a non-significant effect, whereas there could be a significant one in the peaks. Overall, classical regression coefficients are not significantly different from $Q R$ coefficients.

QR coefficients for pressure are neither significant nor different from a classical regression until lag 7. From this lag on, they become significant in quantiles higher than the median. The coefficients are larger in the peaks (particularly at lag 7). Note that coefficients are positive, indicating an increase in hospitalizations when pressure increases at lags 3, 7, and 14. Coefficients are negative the same day, but they are non-significant.

Coefficients for precipitations are mainly non-significant. Some coefficients are, around the $80 \%$ quantile. QR and classical regression CI cross each other for every estimation.

The QR coefficient curve for snow is similar to the one for temperature. It follows a decreasing (until the $20 \%$ quantile), increasing (until the $40 \%$ quantile) and again decreasing pattern. At lags 0 and 3, coefficients are positive and mainly significant, except in peaks higher than the $95 \%$ quantile. At lags 7 and 14, the situation is inversed since most of the coefficients become non-significant, whereas those in peaks become so. Note that $Q R$ coefficients quantiles around the median are positive but become negative in the peaks. In those peaks, they are furthermore larger in absolute value than in other quantiles, and QR and classical mean regression $\mathrm{CI}$ do not cross.

\subsection{Deaths}

Figure 3 provides results for QR estimated coefficients. Regarding temperature, an increase is associated with a decrease in deaths as the estimated coefficients are negative. Moreover, this effect is significant for all quantiles and lags, getting larger (in absolute value) in higher quantiles and lags. QR coefficients in the peaks are indeed 1.5 to 2 times stronger when compared to those in low or median quantiles. Finally, QR coefficients are not different from those estimated by classical regression, except at lag 14. At this lag, classical mean regression coefficients are larger and smaller than those of $\mathrm{QR}$ in low and high quantiles respectively.

Humidity coefficients are either constant through the estimated quantiles or decreasing. Humidity coefficients are non-significant on the same day but are significant for the other lags. Estimated coefficients are negative, with the highest intensity in the peaks. Furthermore, the value of the $99 \%$ quantile coefficient grows larger from lag 0 to 14 (from -0.5 to -1.5 ). It is, however, not possible to differentiate QR estimations from those of classical regression.

In contrast to humidity, pressure is significant only for exposure on the same day, between the median and the 95\% quantile. Estimated coefficients are negative and not distinguishable from a classical regression. Notice that estimated QR coefficients are the strongest in peaks starting from the $92.5 \%$ quantile.

Precipitation coefficients are mainly non-significant. A small portion is significant, under the $20 \%$ quantile at lag 14 .

Finally, snow estimated coefficients are non-significant at lag 14, though they are for the other lags. Snow is associated with more deaths in peaks, where estimated coefficients are the largest (especially for exposure on the same day). Besides, on the same day and for the peaks higher than the $90 \%$ quantile, QR coefficients are different and larger than classical mean regression. 

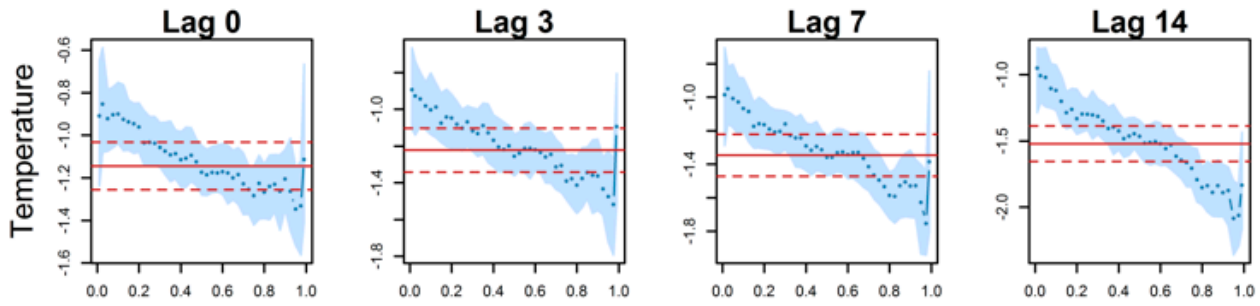

Quantile
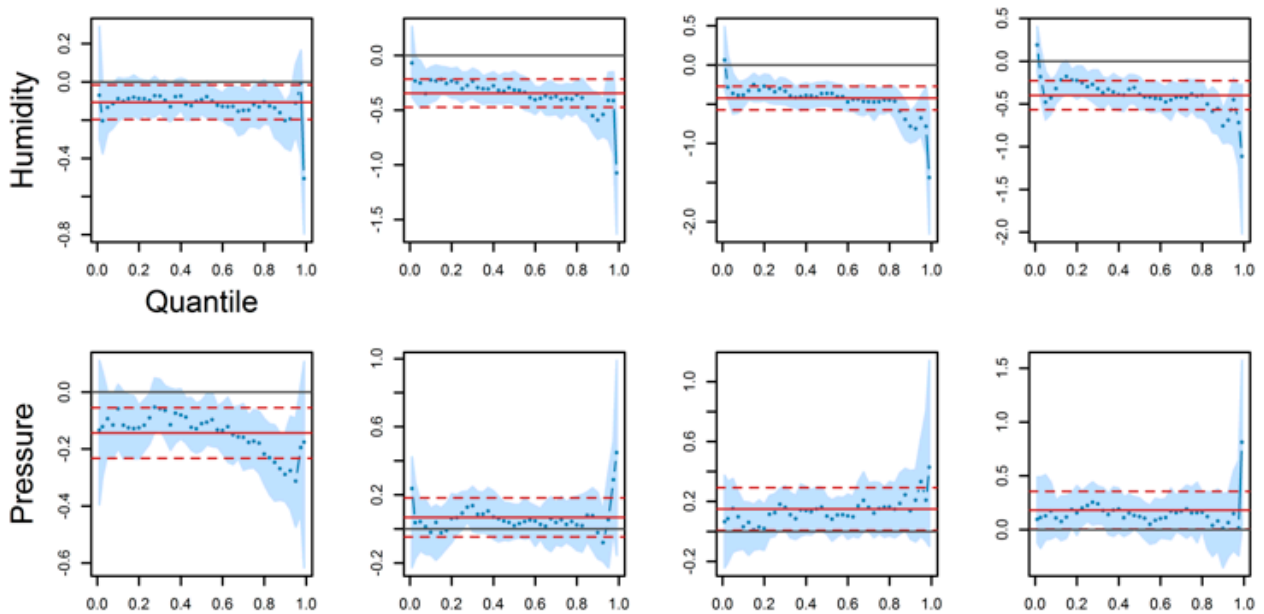

Quantile
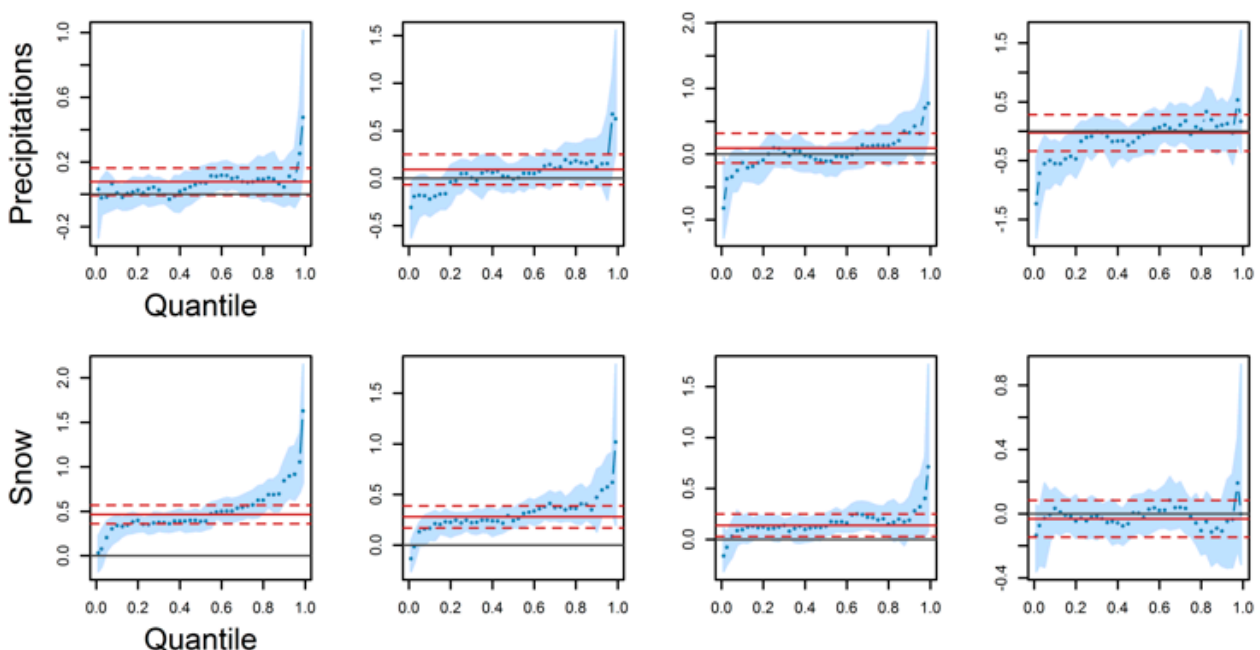

Figure 3. QR (blue dots) and classical mean regression (red full line) coefficients against quantiles for deaths in Montreal. 95\% confidence intervals are shown in light blue for QR and in red dashed lines for classical mean regression.

\section{Discussion}

Each meteorological variable is discussed below, followed by general considerations.

\subsection{Temperature}

The temperature turned out to be the most important meteorological variable in terms of statistical significance and coefficient values. A negative association was found as all the estimated coefficients were negative, meaning that lower temperatures are associated with a higher number of CVD hospitalizations and deaths in the investigated quantiles. One possible explanation would be that CVD peaks mainly occur during cold periods [41-43]. This negative association between temperature and CVD health has been found in other parts of the world, such as Lille in France [44] or Honk Kong in China [45]. Specifically, in Montreal, it has been shown that found that cold weather induces more CVD deaths than 
hot weather [46,47]. Furthermore, absolute values for the coefficients increased in higher quantiles, which indicates stronger relationships in the peaks.

\subsection{Atmospheric Pressure}

Opposite results were found concerning the effect of pressure on CVD deaths and hospitalizations. Indeed, an increase in pressure was associated with a decrease in deaths (mainly on the same day, lag 0). Besides, this effect was larger in the peaks than in lower quantiles. Schwartz [48] and Vaduganathan et al. [49] also found a negative association for pressure in the United States and Italy, respectively, though results were for deaths due to all causes for the first and not focusing on the peaks for both. On the contrary, a positive association with deaths due to myocardial infarction and heart failure has been found in previous studies $[44,50,51]$.

For hospitalizations, pressure coefficients were non-significant at lag 0. Starting from lag 3, positive coefficients were then obtained. In Québec, another study found that an increase in pressure in the previous 7 days was associated with a higher risk of being hospitalized for heart failure [51]. Fong and $\mathrm{Ma}$ [45] also discovered an association between pressure and CVD hospitalizations in China with lags up to 2 weeks and mentioned that high-pressure systems can produce stagnation episodes (i.e., pollutant accumulation due to weak winds). Notice that atmospheric pressure daily measures were used in this study, but pressure variations also appear to be detrimental to acute myocardial infarctions, especially over one day [52]. Therefore, more studies are needed to explore the relationships between atmospheric pressure and CVD, especially peaks.

\subsection{Relative Humidity}

In this study, relative humidity did not have a significant impact on hospitalizations. This absence of effect has been reported in China and the United States [37,45]. However, Abrignani et al. [53] found a significant relationship between daily hospital admissions due to angina pectoris and relative humidity, although they considered a particular subset of CVDs.

Concerning deaths, a negative and significant association that increased with the lag was found where the effects were stronger for the peaks. Masselot, et al. [46] also found a significant association in Montreal. They uncovered a link between CVD deaths and hospitalizations with humidity at large scales (periodicity of several years). In our study, considered lags spread out from 0 to 14 days, therefore results are not comparable. It is widely accepted that humidity influences perceived temperature, and those two variables are usually studied together in a health context $[54,55]$.

\subsection{Snow Height}

Snow height exhibited inverse relationships for hospitalizations (increasing curve) and deaths (decreasing curve). Furthermore, QR coefficients are significant in the peaks at lags 14 and $0-3$, respectively. This suggests an immediate effect of the snow on death peaks but a more prolonged effect on hospitalization peaks. QR coefficients in the peaks are also opposite at the mentioned lags: negative for hospitalizations and positive for deaths. An increase in snow is thus associated with fewer hospitalizations but more deaths when focusing on the peaks. Important and long snowfalls might discourage people from going out, therefore decreasing their exposure [56,57]. On the other hand, there is an increased risk for death and hospitalization due to myocardial infarction immediately after a snowfall in Québec [14], associated with snow shoveling. Those consequences of snowfall are visible in this study around the median, but the negative association in the hospitalization peaks has not been explored yet in the literature.

\subsection{Precipitations}

Precipitation effects were mainly non-significant on CVD deaths and hospitalizations. Some quantiles for hospitalizations (at every lag) revealed significant negative coefficients, 
which means that an increase in precipitations was associated with a decrease in hospitalizations. However, this effect was non-significant in the peaks. As with the other meteorological variables, this heterogeneous impact would not be revealed using a classical regression. To the best of our knowledge, though some studies link health conditions to precipitations (such as hydric diseases [58]), no study has focused on CVDs. As with humidity, precipitations are rarely investigated alone when studying health impacts, more frequently with temperature or snow height $[59,60]$.

\subsection{General Considerations}

Overall, classical regression and QR coefficients were similar as their $95 \% \mathrm{CI}$ crossed. Notable exceptions were in the peaks. As $Q R$ coefficients varied from one quantile to another, estimated associations were most of the time stronger in the health peaks than in any other quantiles. This coefficient heterogeneity could not be investigated using classical regression and is one of the main advantages of $\mathrm{QR}$. Besides, $\mathrm{QR}$ allows reconstructing the entire conditional distribution rather than the conditional mean, as advocated by other authors in health research [61-63]. In particular, Siciliani et al. [62] found that the effect of the dependent variables is larger at the higher conditional quantiles, as found in the present study (e.g., temperature effect in Figure 2).

Another difference that can be observed when using $Q R$ is the sign inversion for QR parameters. For instance, Marrie et al. [61] found opposing effects between a mean regression and a $90 \% \mathrm{QR}$. This situation occurred in this study, such as the case of snow with hospitalizations at lag 14 (Figure 2). QR coefficients around the mean were estimated positive, whereas they were negative starting from the $90 \%$ quantile, thus opposing the classical mean regression. Therefore, $\mathrm{QR}$ is relevant in the health peak study as it allows comparing the conditional mean to the high quantiles, where results may be larger or even inverse. More generally, it complements classical regression analysis by providing a conditional distribution [64].

In fields other than environmental health, heterogeneous and accentuated effects for independent variables in the high conditional quantiles have also been observed (climatology or hydrogeology [65,66]). Authors support QR use as it can decompose relationships in quantiles other than the median. More recently, $Q R$ has been used in the same spirit to study the effects of home quarantine during the COVID-19 pandemic [67]. The authors evaluated multiple variables on the distribution of happiness and found that low and high quantiles were not influenced by the same variables. In other words, people with increased happiness (high quantiles) did not experience the quarantine at home the same way that people with decreased happiness (low quantiles) did.

\subsection{Limitations}

Daily aggregation for the health variables did not allow for the inclusion of relevant individual variables, such as comorbidities or life habits (smoking, nutrition, or physical exercise). Those variables have an impact on CVD occurrence [7-9]. Furthermore, besides meteorological variables, atmospheric pollution variables should also be included in future research $[68,69]$.

From a statistical point of view, nonlinear $Q R$ could be used to investigate specific quantiles [61]. However, since nonlinear $\mathrm{QR}$ produces a regression curve instead of a regression line for each quantile, chances that multiple curves cross each other would be increased (a non-trivial issue known as crossing QR, for which research is still active $[70,71]$ ), leading to invalid results.

\section{Conclusions}

This paper aimed at studying relationships between CVD health and meteorological conditions using QR, examining health peaks and lower conditional quantiles at the same time. Different lags and multiple quantiles have been investigated. Even though the focus 
here is on CVDs, QR could also be used to investigate possible relationships between meteorological conditions and any other chronic disease.

In previous studies, the temperature has shown a significant effect. This is similar to the results in this study, confirming the importance of temperature on CVD health. Moreover, $\mathrm{QR}$ has allowed for more precise estimations and has shown the heterogeneous effects of meteorological conditions in the health variables quantiles. In particular, impacts were found to be stronger in health peaks compared to median quantiles. This result could not be obtained using a classical regression, as the information would be "diluted". Therefore, along with meteorological forecasting, those results could be useful for health peak forecasting and its management in health warnings and services.

Finally, this study supports the idea of completing classical health and meteorological conditions studies with health peaks studies. Doing so would result in more complete estimations of health variable conditional distributions.

Author Contributions: Conceptualization, Y.M.C., F.C., B.A., D.B. and P.G.; Methodology, Y.M.C. and F.C.; Software, Y.M.C.; Validation, F.C., D.B. and P.G.; Formal Analysis, Y.M.C. and F.C.; Investigation, Y.M.C. and F.C.; Resources, F.C., D.B. and P.G.; Data Curation, Y.M.C.; Writing-Original Draft Preparation, Y.M.C.; Writing—Review \& Editing, Y.M.C., F.C., B.A., D.B. and P.G.; Visualization, Y.M.C.; Supervision, F.C., D.B. and P.G.; Project Administration, F.C., D.B. and P.G.; Funding Acquisition,: F.C., B.A., D.B. and P.G. All authors have read and agreed to the published version of the manuscript.

Funding: This work was funded by the Fonds Vert du Québec, in the context of Action 21 of the 2006-2012 Québec Government Action Plan on Climate Change, and by the INSPQ.

Institutional Review Board Statement: For The health data, the study was conducted according to an agreement established between the INSPQ and the government of Québec as part of the ministerial plan of multithematic health surveillance. This plan has received its ethics approval by the Public Health Ethics Committee in January 2010 (ISBN: 978-2-550-58576-3; https:/ / www.inspq. qc.ca/publications/1124).

Informed Consent Statement: Not applicable.

Data Availability Statement: Data are not available, due to governmental privacy policy.

Acknowledgments: The authors thank the Institut national de la santé publique du Québec for access to the health data. The authors also wish to thank Jean-Xavier Giroux (INRS-ETE) for his expertise on the data. The authors had many discussions with Pierre Masselot (The London School of Hygiene \& Tropical Medicine), who significantly improved the quality of this paper and graciously provided the code for Figure 1.

Conflicts of Interest: The authors declare no conflict of interest.

\section{References}

1. Abrignani, M.G.; Corrao, S.; Biondo, G.B.; Lombardo, R.M.; Di Girolamo, P.; Braschi, A.; Di Girolamo, A.; Novo, S. Effects of ambient temperature, humidity, and other meteorological variables on hospital admissions for angina pectoris. Eur. J. Prev. Cardiol. 2012, 19, 342-348. [CrossRef] [PubMed]

2. Afshin, A.; Micha, R.; Khatibzadeh, S.; Mozaffarian, D. Consumption of nuts and legumes and risk of incident ischemic heart disease, stroke, and diabetes: A systematic review and meta-analysis. Am. J. Clin. Nutr. 2014, 100, 278-288. [CrossRef]

3. Auger, N.; Potter, B.J.; Smargiassi, A.; Bilodeau-Bertrand, M.; Paris, C.; Kosatsky, T. Association between quantity and duration of snowfall and risk of myocardial infarction. Can. Med. Assoc. J. 2017, 189, E235-E242. [CrossRef] [PubMed]

4. Auliciems, A.; Frost, D. Temperature and cardiovascular deaths in Montreal. Int. J. Biometeorol. 1989, 33, 151-156. [CrossRef] [PubMed]

5. Austin, P.C.; Tu, J.V.; Daly, P.A.; Alter, D.A. The use of quantile regression in health care research: A case study examining gender differences in the timeliness of thrombolytic therapy. Stat. Med. 2004, 24, 791-816. [CrossRef] [PubMed]

6. Baker-Blocker, A. Winter weather and cardiovascular mortality in Minneapolis-St. Paul. Am. J. Public Health 1982, 72, $261-265$. [CrossRef] [PubMed]

7. Barnett, A.G.; Hajat, S.; Gasparrini, A.; Rocklöv, J. Cold and heat waves in the United States. Environ. Res. 2012, 112, 218-224. [CrossRef]

8. Bayentin, L.; El Adlouni, S.; Ouarda, T.B.; Gosselin, P.; Doyon, B.; Chebana, F. Spatial variability of climate effects on ischemic heart disease hospitalization rates for the period 1989-2006 in Quebec, Canada. Int. J. Health Geogr. 2010, 9, 5. [CrossRef] 
9. Bergh, I.H.; Skare, Ø.; Aase, A.; Klepp, K.-I.; Lien, N. Weight development from age 13 to 30 years and adolescent socioeconomic status: The Norwegian Longitudinal Health Behaviour study. Int. J. Public Health 2015, 61, 465-473. [CrossRef]

10. Bind, M.-A.; Peters, A.; Koutrakis, P.; Coull, B.; Vokonas, P.; Schwartz, J. Quantile Regression Analysis of the Distributional Effects of Air Pollution on Blood Pressure, Heart Rate Variability, Blood Lipids, and Biomarkers of Inflammation in Elderly American Men: The Normative Aging Study. Environ. Health Perspect. 2016, 124, 1189-1198. [CrossRef]

11. Blais, C.; Rochette, L. Portrait de l'Ensemble des Maladies Vasculaires au Québec: Prévalence, Incidence et Mortalité; INSPQ: Québec City, QC, Canada, 2018; p. 19.

12. Cannon, A.J. Non-crossing nonlinear regression quantiles by monotone composite quantile regression neural network, with application to rainfall extremes. Stoch. Environ. Res. Risk Assess. 2018, 32, 3207-3225. [CrossRef]

13. Chebana, F.; Martel, B.; Gosselin, P.; Giroux, J.-X.; Ouarda, T.B. A general and flexible methodology to define thresholds for heat health watch and warning systems, applied to the province of Québec (Canada). Int. J. Biometeorol. 2013, 57, 631-644. [CrossRef]

14. Chiu, Y.; Chebana, F.; Abdous, B.; Bélanger, D.; Gosselin, P. Mortality and morbidity peaks modeling: An extreme value theory approach. Stat. Methods Med. Res. 2018, 27, 1498-1512. [CrossRef]

15. Chiu, Y.; Chebana, F.; Abdous, B.; Bélanger, D.; Gosselin, P. Étude des Relations Entre les Pics de Maladies Cardiovasculaires et les Conditions Météorologiques par la Régression Quantile, dans les Communautés Métropolitaines de Québec et de Montréal (Québec); Institut National de la Recherche Scientifique: Québec City, QC, Canada, 2017; p. 74.

16. Chiu, Y.; Chebana, F.; Bélanger, D.; Gosselin, P.; Abdous, B. Modélisation des Pics Sanitaires de Maladies Cardiovasculaires en Fonction de la Météo dans les Communautés Métropolitaines de Québec et Montréal; Institut National de la Recherche Scientifique: Québec City, QC, Canada, 2016; p. 128.

17. Curriero, F.C.; Patz, J.A.; Rose, J.B.; Lele, S. The association between extreme precipitation and waterborne disease outbreaks in the United States, 1948-1994. Am. J. Public Health 2001, 91, 1194-1199. [CrossRef] [PubMed]

18. Danet, S.; Richard, F.; Montaye, M.; Beauchant, S.; Lemaire, B.; Graux, C.; Cottel, D.; Marecaux, N.; Amouyel, P. Unhealthy effects of atmospheric temperature and pressure on the occurrence of myocardial infarction and coronary deaths. A 10-year survey: The Lille-World Health Organization MONICA project (Monitoring trends and determinants in cardi-ovascular disease). Circulation 1999, 100, E1-E7. [CrossRef] [PubMed]

19. De Zea Bermudez, P.; Mendes, Z. Extreme value theory in medical sciences: Modeling total high cholesterol levels. J. Stat. Theory Pract. 2012, 6, 468-491. [CrossRef]

20. Dinas, P.C.; Koutedakis, Y.; Flouris, A.D. Effects of active and passive tobacco cigarette smoking on heart rate variability. Int. J. Cardiol. 2013, 163, 109-115. [CrossRef] [PubMed]

21. Dominici, F.; McDermott, A.; Zeger, S.L.; Samet, J.M. On the use of generalized additive models in time-series studies of air pollution and health. Am. J. Epidemiol. 2002, 156, 193-203. [CrossRef]

22. Fong, T.; Ma, E. Effects of meteorological parameters on hospital admission for respiratory and cardiovascular diseases. J. Public Health 2013, 21, 175-182. [CrossRef]

23. Franklin, B.A.; Brook, R.; Arden Pope, C., 3rd. Air pollution and cardiovascular disease. Curr. Probl. Cardiol. 2015, 40, 207-238. [CrossRef]

24. Gagné, M. Principales Causes d'Hospitalisations au Québec, Hommes et Femmes Confondus; INSPQ: Québec City, QC, Canada, 2017.

25. Gasparrini, A.; Guo, Y.; Hashizume, M.; Lavigne, E.; Zanobetti, A.; Schwartz, J.; Tobías, A.; Tong, S.; Rocklöv, J.; Forsberg, B.; et al. Mortality risk attributable to high and low ambient temperature: A multicountry observational study. Lancet 2015, 386, 369-375. [CrossRef]

26. Giroux, J.X.; Chebana, F.; Bélanger, D.; Gloaguen, E.; Ouarda, T.B.M.J.; Saint-Hilaire, A. Projet M1: Comparaison de l'Utilisation des Moyennes Spatiales à Celle du Krigeage, Appliquée à la Relation Mortalité par MCV-Météorologie, au Québec, de 1996 à 2007. Rapport Final; INRS-ETE: Québec City, QC, Canada, 2013.

27. Goldberg, M.S.; Gasparrini, A.; Armstrong, B.; Valois, M.-F. The short-term influence of temperature on daily mortality in the temperate climate of Montreal, Canada. Environ. Res. 2011, 111, 853-860. [CrossRef] [PubMed]

28. Hao, L.; Naiman, D.Q.; Naiman, D.Q. Quantile Regression; Sage Publications: Thousand Oaks, CA, USA, 2007.

29. Hirschi, M.; Seneviratne, S.I.; Alexandrov, V.; Boberg, F.; Boroneant, C.; Christensen, O.B.; Formayer, H.; Orlowsky, B.; Stepanek, P. Observational evidence for soil-moisture impact on hot extremes in southeastern Europe. Nat. Geosci. 2011, 4, 17-21. [CrossRef]

30. Hoek, G.; Krishnan, R.M.; Beelen, R.; Peters, A.; Ostro, B.; Brunekreef, B.; Kaufman, J.D. Long-term air pollution exposure and cardio-respiratory mortality: A review. Environ. Health 2013, 12, 43. [CrossRef]

31. Houck, P.D.; Lethen, J.E.; Riggs, M.W.; Gantt, D.S.; Dehmer, G.J. Relation of atmospheric pressure changes and the occurrences of acute myocardial infarction and stroke. Am. J. Cardiol. 2005, 96, 45-51. [CrossRef] [PubMed]

32. IPCC. The Physical Science Basis: Working Group I Contribution to the Fifth Assessment Report of the Intergovernmental Panel on Climate Change; Cambridge University Press: Cambridge, UK; New York, NY, USA, 2013; 1007p.

33. Jagger, T.H.; Elsner, J.B. Modeling tropical cyclone intensity with quantile regression. Int. J. Climatol. 2009, $29,1351-1361$. [CrossRef]

34. Jurečková, J. Robust Quantile Regression. In Wiley StatsRef: Statistics Reference Online; John Wiley \& Sons, Ltd.: Chichester, UK, 2014. [CrossRef]

35. Knowlton, K.; Rotkin-Ellman, M.; King, G.; Margolis, H.G.; Smith, D.; Solomon, G.; Trent, R.; English, P. The 2006 California heat wave: Impacts on hospitalizations and emergency department visits. Environ. Health Perspect. 2009, 117, 61-67. [CrossRef] 
36. Koenker, R. Quantile Regression; Cambridge University Press: Cambridge, UK, 2005.

37. Koenker, R.; Bassett, G. Regression Quantiles. Econometrica 1978, 46, 33-50. [CrossRef]

38. Landrigan, P.J.; Fuller, R.; Acosta, N.J.R.; Adeyi, O.; Arnold, R.; Basu, N.N.; Baldé, A.B.; Bertollini, R.; Bose-O'Reilly, S.; Boufford, J.I.; et al. The Lancet Commission on pollution and health. Lancet 2018, 391, 462-512. [CrossRef]

39. Lavigne, E.; Gasparrini, A.; Wang, X.; Chen, H.; Yagouti, A.; Fleury, M.D.; Cakmak, S. Extreme ambient temperatures and cardiorespiratory emergency room visits: Assessing risk by comorbid health conditions in a time series study. Environ. Health 2014, 13, 5. [CrossRef] [PubMed]

40. Lelieveld, J.; Klingmüller, K.; Pozzer, A.; Pöschl, U.; Fnais, M.; Daiber, A.; Münzel, T. Cardiovascular disease burden from ambient air pollution in Europe reassessed using novel hazard ratio functions. Eur. Heart J. 2019, 40, 1590-1596. [CrossRef]

41. Lim, Y.-H.; Hong, Y.-C.; Kim, H. Effects of diurnal temperature range on cardiovascular and respiratory hospital admissions in Korea. Sci. Total Environ. 2012, 417-418, 55-60. [CrossRef] [PubMed]

42. Lin, S.; Luo, M.; Walker, R.J.; Liu, X.; Hwang, S.A.; Chinery, R. Extreme high temperatures and hospital admissions for respiratory and cardiovascular diseases. Epidemiology 2009, 20, 738-746. [CrossRef]

43. Lu, H.; Nie, P.; Qian, L. Do quarantine experiences and attitudes towards COVID-19 affect the distribution of mental health in China? A quantile regression analysis. Appl. Res. Qual. Life 2020, 16, 1925-1942. [CrossRef]

44. Marrie, R.A.; Dawson, N.V.; Garland, A. Quantile regression and restricted cubic splines are useful for exploring relationships between continuous variables. J. Clin. Epidemiol. 2009, 62, 511-517. [CrossRef]

45. Martel, B.; Ouarda, T.B.M.J.; Vanasse, A.; Chebana, F.; Orzanco, M.G.; Charron, C.; Courteau, J.; Asghari, S.; Gosselin, P. Modélisation des Fractures de la Hanche en Fonction de Variables Météorologiques à l'Aide du Modèle GAM dans Deux Régions Métropolitaines du Québec, Canada; INRS, Centre Eau, Terre et Environnement: Quebec City, QC, Canada, 2010; 256p.

46. Masselot, P.; Chebana, F.; Belanger, D.; St-Hilaire, A.; Abdous, B.; Gosselin, P.; Ouarda, T. Aggregating the response in time series regression models, applied to weather-related cardiovascular mortality. Sci. Total Environ. 2018, 628-629, 217-225. [CrossRef]

47. Masselot, P.; Chebana, F.; Bélanger, D.; St-Hilaire, A.; Abdous, B.; Gosselin, P.; Ouarda, T.B.M.J. EMD-regression for modelling multi-scale relationships, and application to weather-related cardiovascular mortality. Sci. Total Environ. 2018, 612, 1018-1029. [CrossRef]

48. Mitchell, J.A.; Dowda, M.; Pate, R.R.; Kordas, K.; Froberg, K.; Sardinha, L.B.; Kolle, E.; Page, A. Physical Activity and Pediatric Obesity: A Quantile Regression Analysis. Med. Sci. Sports Exerc. 2017, 49, 466-473. [CrossRef] [PubMed]

49. Mourtzoukou, E.G.; Falagas, M.E. Exposure to cold and respiratory tract infections [Review Article]. Int. J. Tuberc. Lung Dis. 2007, $11,938-943$.

50. Newby, D.E.; Mannucci, P.M.; Tell, G.S.; Baccarelli, A.A.; Brook, R.D.; Donaldson, K.; Forastiere, F.; Franchini, M.; Franco, O.; Graham, I.; et al. Expert position paper on air pollution and cardiovascular disease. Eur. Heart J. 2015, 36, 83-93. [CrossRef] [PubMed]

51. O'Connor, E.A.; Evans, C.V.; Rushkin, M.C.; Redmond, N.; Lin, J.S. Behavioral counseling to promote a healthy diet and physical activity for cardiovascular disease prevention in adults with cardiovascular risk factors: Updated evidence report and systematic review for the US Preventive Services Task Force. JAMA 2020, 324, 2076-2094. [CrossRef]

52. Bourque, A. Vers l'Adaptation. Synthèse des Connaissances sur les Changements Climatiques au Québec. Partie 1: Évolution Climatique au Québec; Ouranos: Montreal, QC, Canada, 2015; 114p.

53. Phung, D.; Guo, Y.; Thai, P.K.; Rutherford, S.; Wang, X.; Nguyen, M.; Do, C.M.; Nguyen, N.H.; Alam, N.; Chu, C. The effects of high temperature on cardiovascular admissions in the most populous tropical city in Vietnam. Environ. Pollut. 2016, 208, 33-39. [CrossRef]

54. Phung, D.; Thai, P.K.; Guo, Y.; Morawska, L.; Rutherford, S.; Chu, C. Ambient temperature and risk of cardiovascular hospitalization: An updated systematic review and meta-analysis. Sci. Total Environ. 2016, 550, 1084-1102. [CrossRef] [PubMed]

55. Robine, J.-M.; Cheung, S.L.; Le Roy, S.; Van Oyen, H.; Griffiths, C.; Michel, J.-P.; Herrmann, F.F. Death toll exceeded 70,000 in Europe during the summer of 2003. Comptes Rendus Biol. 2008, 331, 171-178. [CrossRef]

56. Schwartz, J. The Distributed Lag between Air Pollution and Daily Deaths. Epidemiology 2000, 11, 320-326. [CrossRef]

57. Schwartz, J.; Samet, J.M.; Patz, J.A. Hospital admissions for heart disease: The effects of temperature and humidity. Epidemiology 2004, 15, 755-761. [CrossRef]

58. Sharaf, M.F.; Mansour, E.I.; Rashad, A.S. Child nutritional status in Egypt: A comprehensive analysis of socio-economic determinants using a quantile regression approach. J. Biosoc. Sci. 2011, 51, 1-17. [CrossRef]

59. Siciliani, L.; Sivey, P.; Street, A. Differences in Length of Stay for Hip Replacement between Public Hospitals, Specialised Treatment Centres and Private Providers: Selection or Efficiency? Health Econ. 2013, 22, 234-242. [CrossRef] [PubMed]

60. Sottile, G.; Frumento, P. Parametric estimation of non-crossing quantile functions. Stat. Model. 2021, $1471082 X 211036517$. [CrossRef]

61. Statistics Canada. Leading Causes of Death, Total Population, by Age Group. 2021. Available online: https://open.canada.ca/ data/en/dataset/99993095-becb-454b-9568-e36ae631824e (accessed on 9 December 2021).

62. Taylor, F.; Ward, K.; Moore, T.H.; Burke, M.; Davey Smith, G.; Casas, J.P.; Ebrahim, S. Statins for the primary prevention of cardiovascular disease. Cochrane Database Syst. Rev. 2011, CD004816. [CrossRef]

63. Thomas, M.; Lemaitre, M.; Wilson, M.L.; Viboud, C.; Yordanov, Y.; Wackernagel, H.; Carrat, F. Applications of Extreme Value Theory in Public Health. PLoS ONE 2016, 11, e0159312. [CrossRef] 
64. Vaduganathan, M.; De Palma, G.; Manerba, A.; Goldoni, M.; Triggiani, M.; Apostoli, P.; Dei Cas, L.; Nodari, S. Risk of Cardiovascular Hospitalizations from Exposure to Coarse Particulate Matter (PM10) Below the European Union Safety Threshold. Am. J. Cardiol. 2016, 117, 1231-1235. [CrossRef]

65. Vanasse, A.; Talbot, D.; Chebana, F.; Bélanger, D.; Blais, C.; Gamache, P.; Giroux, J.-X.; Dault, R.; Gosselin, P. Effects of climate and fine particulate matter on hospitalizations and deaths for heart failure in elderly: A population-based cohort study. Environ. Int. 2017, 106, 257-266. [CrossRef]

66. Wang, X.; Ouyang, Y.; Liu, J.; Zhu, M.; Zhao, G.; Bao, W.; Hu, F.B. Fruit and vegetable consumption and mortality from all causes, cardiovascular disease, and cancer: Systematic review and dose-response meta-analysis of prospective cohort studies. BMJ 2014, 349, g4490. [CrossRef] [PubMed]

67. World Health Organisation. The Top 10 Causes of Death. 2020. Available online: https://www.who.int/news-room/fact-sheets/ detail/the-top-10-causes-of-death (accessed on 17 September 2021).

68. Yan, B.; Chebana, F.; Masselot, P.; Campagna, C.; Gosselin, P.; Ouarda, T.; Lavigne, É. A cold-health watch and warning system, applied to the province of Quebec (Canada). Sci. Total Environ. 2020, 741, 140188. [CrossRef]

69. Yang, J.; Ou, C.-Q.; Song, Y.-F.; Li, L.; Chen, P.-Y.; Liu, Q.-Y. Estimating years of life lost from cardiovascular mortality related to air pollution in Guangzhou, China. Sci. Total Environ. 2016, 573, 1566-1572. [CrossRef] [PubMed]

70. Yang, J.; Yin, P.; Zhou, M.; Ou, C.-Q.; Guo, Y.; Gasparrini, A.; Liu, Y.; Yue, Y.; Gu, S.; Sang, S.; et al. Cardiovascular mortality risk attributable to ambient temperature in China. Heart 2015, 101, 1966-1972. [CrossRef] [PubMed]

71. Zeng, J.; Zhang, X.; Yang, J.; Bao, J.; Xiang, H.; Dear, K.; Liu, Q.; Lin, S.; Lawrence, W.R.; Lin, A.; et al. Humidity may modify the relationship between temperature and cardiovascular mortality in Zhejiang Province, China. Int. J. Environ. Res. Public Health 2017, 14, 1383. [CrossRef] 